\title{
Devastating urban flooding and dengue outbreak during the COVID-19 pandemic in Pakistan
}

\author{
Muhammad Junaid Tahir*1,2 (D), Ahsun Rizwan Siddiqi ${ }^{3}$, Irfan Ullah ${ }^{4}$, Ali Ahmed ${ }^{5}$, Juman Dujaili ${ }^{5}$, Muhammad Saqlain ${ }^{6}$ \\ Received: 14 Sep 2020 \\ Published: 15 Dec 2020
}

\begin{abstract}
Pakistan has recently been overwhelmed by extreme torrential rains, with its most populous city of Karachi experiencing its worst floods in almost a century. Poor flood control and water disposal facilities have led to an immense risk of another dengue outbreak, with multiple cases being reported recently. The enormous accumulation of stagnant water in urban areas is a major source of mosquito breeding and transmission. Historical data has shown the correlation between the number of dengue cases and average rainfall in the region. The monsoon rains have pounded at a time where health authorities are battling to contain the Coronavirus (COVID-19) pandemic. There is a need to implement centralized dengue control strategies to undertake large scale water drainage, sanitation, and disinfection drives in disaster-stricken areas alongside public health awareness programs to combat the after-effects of this natural calamity.
\end{abstract}

Keywords: Dengue, COVID-19, Floods, Rain, Pakistan

Conflicts of Interest: None declared

Funding: None

*This work has been published under CC BY-NC-SA 1.0 license.

Copyright $\odot$ Iran University of Medical Sciences

Cite this article as: Junaid Tahir M, Rizwan Siddiqi A, Ullah I, Ahmed A, Dujaili J, Saqlain M. Devastating urban flooding and dengue outbreak during the COVID-19 pandemic in Pakistan. Med J Islam Repub Iran. 2020 (15 Dec);34:169. https://doi.org/10.47176/mjiri.34.169

\section{To the Editor,}

Pakistan has recently been ravaged by extreme torrential rains over the last few weeks, with its most populous city of Karachi experiencing its worst floods in almost a century (1). Poor flood control and abysmal water disposal facilities have increased the risk of dengue, malaria, and other waterborne disease epidemics (2). The enormous accumulation of stagnant water within residential and commercial areas has immensely increased the risk of another dengue outbreak. The monsoon rains are pounding at a time when the authorities are trying to contain the spread of Coronavirus, which has caused more than 6345 deaths in the country since February (3). In this year, 2020, the province of Sindh has reported 733 cases of dengue in the first 8 months, with about $92 \%$ of the cases being reported in Karachi (2). During the last 3 days, at least 10 more dengue cases have been reported in the city (2) and the situation could worsen in the next few weeks. Last year in 2019, Pakistan recorded the highest number of dengue cases in September and October, 10903 and 8489, respectively (4). Pakistan is faced with the problems of the COVID-19 pandemic, extreme climatic conditions, and another dengue outbreak in the coming months would be devastating for an already weakened health care system.

Dengue fever, along with its severe manifestations, Dengue Hemorrhagic Fever (DHF) and Dengue Shock Syndrome (DSS), has emerged as a major public health threat, spreading to many tropical and subtropical countries in the world (5). An estimated 50 million dengue infections occur annually in the world (5). Despite the risk of infection existing in many countries, Southeast Asia bears a high burden of dengue (5). Outbreaks of dengue are interlinked with the monsoon season, which spans from July to October (6). Pakistan gets its major annual rainfalls during the monsoons, which is coupled with poor drainage systems and poor infrastructure (6). Water retained on rooftops and containers after heavy rain episodes become the ideal breeding spots for Aedes mosquitoes (6). In 2010, Pakistan was badly affected by heavy rainfall and massive flooding, which directly affected 14-20 million people (7). These

3. Wah Medical College, affiliated with University of Health Sciences, Wah, Pakistan

4. Kabir Medical College, Gandhara University, Peshawar, Pakistan

5. School of Pharmacy, Monash University, Bandar Sunway, Malaysia

6. Department of Pharmacy, Quaid-I-Azam University, Islamabad, Pakistan 
floods were followed by an enormous spike in the number of dengue cases due to increased breeding opportunities for vector mosquitoes (8). As a consequence, the number of dengue cases reported in 2010 was the then highest recorded in Pakistan. Studies have shown that the amount of rainfall is the single most important factor for dengue virus transmission (9). The historical data indicates that the number of reported dengue cases correlate with the average amount of rainfall (9). Different water and vector borne diseases have already emerged after recent heavy flooding and without urgent large scale disinfection programs, a sharp spike in dengue cases could be seen in the next few months.

Dengue fever, a viral disease known to be transmitted by mosquitoes, i.e., Aedes aegypti and Aedes albopictus, and COVID-19 are wearing to distinguish because of their shared clinical and laboratory features (10). The co-occurrence of these 2 infectious diseases could have drastic effects on the community as well as on the economy, especially in low-income and middle-income countries like Pakistan (11). All around the world, dengue surveillance has suffered a lot due to the ongoing pandemic (12). In Pakistan, plans to disinfect water sources in residential colonies and market places are shelved as funds are being utilized for COVID-19 prevention programs. Disruption of such preventive efforts is ominous for the battle against dengue (12).

Dengue control programs should be initiated at the beginning of the monsoon season, and efforts should be focused on reducing the transmission of infection and the treatment of infected patients (13). Early identification and proper clinical management of dengue fever can reduce the case fatality to $<1 \%$ (14). The following measures should be taken immediately to combat a major dengue outbreak in the coming months. (i) Public health authorities should take serious steps to create public awareness about preventive measures. Dengue virus transmission can be prevented or reduced simply by controlling the mosquito vectors or by the interruption of human-vector contact, e.g., using insect repellents, dressing in clothing that cover arms and legs, using permethrin-treated clothing, and using mosquito nets (13). (ii) Geo-informatics should be used to generate dengue heat maps containing regional disease data based on the trends of the last 5 years. These maps should be made public, and health care and sanitation workers should be assigned to each region based on the local disease burden (15). (iii) The public should be advised to cover, empty, and clean water storage containers on a weekly basis and to apply insecticides to outdoor water containers. Hefty fines should be imposed if mosquito breeding sites are detected in households. (iv) Guidelines should be issued to health workers regarding early diagnosis, isolation, and treatment of dengue cases. (v) Lab testing capacities should be increased, and availability of dengue serology and Reverse Transcriptase-Polymerase Chain Reaction (RT-PCR) should be ensured, at least in tertiary care and teaching hospitals. (vi) The governing authorities should prioritize funding and support to reinforce water sanitation, improve sewage systems with adequate city planning, and enforce high standards of hygiene in the country. Municipal authorities should be on their toes after every episode of heavy rainfall to prevent open-air water accumulation. (vii) A centralized control strategy should be implemented in every province and dengue control programs should be enforced in such a way that they incorporate behavioral change at the community level. There is a strong need to improve surveillance at local, provincial, and national levels to develop DisasterPreparedness Programs and Disease Management Systems to prevent the after-effects of extreme climatic conditions and to manage such co-epidemics together.

\section{Acknowledgment}

The authors would like to extend heartfelt graciousness to teachers who provided support at every step of drafting this paper.

\section{Conflict of Interests}

The authors declare that they have no competing interests.

\section{References}

1. Deutsche Welle (DW). Pakistan: Karachi experiences worst floods in almost a century, dozens dead. https://www.dw.com/en/pakistankarachi-experiences-worst-floods-in-almost-a-century-dozens-dead/a54725008. Accessed Sep 8, 2020

2. The News. Waterborne diseases, dengue surge in Karachi after urban flooding. https://www.thenews.com.pk/print/709977-waterbornediseases-dengue-surge-in-karachi-after-urban-flooding. Accessed Sep 8,2020

3. World Health Organization. WHO Health Emergency Dashboard. https://covid19.who.int/region/emro/country/pk. Accessed Sep 8, 2020

4. National Institute of Health Islamabad NIH. Weekly Field Epidemiology Report. https://www.nih.org.pk/wpcontent/uploads/2019/12/49-FELTP-Pakistan-Weekly-

Epidemiological-Report-Dec-02-08-2019.pdf. Accessed July 15, 2020

5. World Health Organization. Dengue in South-East Asia. https://www.who.int/southeastasia/health-topics/dengue. Accessed Sep 8,2020

6. Sabir M, Ali Y, Muhammad N. Forecasting incidence of dengue and selecting best method for prevention. J Pak Med Assoc. 2018;68(9):1383-1386.

7. Word Food Programme. Pakistan flood impact assessment. September 2010 .

https://documents.wfp.org/stellent/groups/public/documents/ena/wfp2 25987.pdf. Accessed Sep 8, 2020

8. Rasheed S, Butlin R, Boots M. A review of dengue as an emerging disease in Pakistan. Public Health. 2013;127(1):11-17.

9. Chanprasopchai P, Pongsumpun P, Tang IM. Effect of Rainfall for the Dynamical Transmission Model of the Dengue Disease in Thailand. Comput Math Methods Med. 2017;2017:2541862.

10. Chen N, Zhou M, Dong X, et al. Epidemiological and clinical characteristics of 99 cases of 2019 novel coronavirus pneumonia in Wuhan, China: a descriptive study. Lancet. 2020;395(10223):507-513.

11. Haqqi A, Awan UA, Ali M, Saqib MAN, Ahmed H, Afzal MS. COVID-19 and dengue virus co-epidemics in Pakistan: A dangerous combination for overburdened healthcare system. J Med Virol. 2020.

12. Voice of America, VOA News. Coronavirus Pandemic Stifles Dengue Prevention Efforts. https://www.voanews.com/covid-19-pandemic/ coronavirus-pandemic-stifles-dengue-prevention-efforts.Accessed July 15,2020

13. Ahmed A, Tanveer M, Khan G, Imran M. Dengue fever again in Pakistan: are we going in the right direction. Public Health. 2017; $152: 153-156$.

14. National Institute of health NIH, Pakistan. Advisory for the Prevention and Control of Dengue Fever. https://www.nih.org.pk/wpcontent/uploads/2019/05/Advisory-for-Dengue-Fever-May-2019.pdf. Accessed Sep 10, 2020

15. Dom NC, Ahmad AH, Latif ZA, Ismail R. Integration of GIS-Based Model with Epidemiological data as a Tool for Dengue Surveillance. EnvironmentAsia. 2017;10(2):135-146. 